\title{
Biochemical, Molecular and Mutagenic Effects of Electromagnetic Fields on Vicia faba L. Seedlings
}

\author{
Reda M. Gaafar, Adel El-Shanshoury, Mohamed R. Eldakak and Mohamed \\ Elhiti $^{\#}$ \\ Botany Department, Faculty of Science, Tanta University, Tanta, 31527, Egypt.
}

\begin{abstract}
$\mathbf{E}$ LECTROMAGNETIC fields (EMFs) consist of two main components electric and magnetic fields. The magnetic fields are the most deleterious and their photons travel in waves-like pattern. These waves penetrate any biological system causing genetic and biochemical changes. In a trail to explore the effects of EMFs on faba bean as a model plant system during seedling stage at cellular, biochemical, and molecular levels, the high-voltage transmission lines as a source of EMFs and aluminum foil as EMFs shelter were used. The effect of EMF direction was investigated by selecting locations at different distances around the high-voltage transmission lines, where seeds were allowed to germinate under different EMF intensities for 10 days. At cellular level, the results showed that EMFs cause severe cytological abnormalities, such as chromosomal breakage, unoriented chromosomes, micronuclei, stickiness, lagging chromosomes, and cytokinesis failure. Such abnormalities were frequent in the Vicia faba seedlings grown directly under the high-voltage transmission lines, where the intensity was $4051 \mu \mathrm{T}$ and the rate of abnormalities increased by decreasing the distance from EMFs source. At biochemical level, $\mathrm{Ca}^{2+}$ binding proteins showed no distinct marker to EMFs, yet arbitrary profiles were observed. At the molecular level, some unique ISSR banding patterns were detected in the EMFs-exposed seedlings. The results indicated no significant differences between the covered and uncovered aluminum foil treatments. Moreover, the plant samples either in the left or right direction exhibited nonsignificant differences. Taken together, these results suggested that a distance of 200 meters from the high-voltage lines is regarded as a safe distance, the effect of EMFs has not inherited in the upcoming generations and aluminum foil cannot protect against EMFs.
\end{abstract}

Keywords: Electromagnetic fields, Mutation, Vicia faba L., Chromosomal aberrations, $\mathrm{Ca}^{2+}-$ binding proteins, Isozymes, ISSRs.

\section{Introduction}

Electromagnetic fields (EMFs) composed of electric filed resulted from differences in voltage, and magnetic fields result from the flow of electric current. Higher-frequency waves of EMF have more energy than lower-frequency waves, and thus generally tend to be more harmful. Artificial sources of EMFs have increased tremendously due to the increasing needs for electricity, telecommunications and electronic devices (Pourlis, 2009). High-voltage power lines, electrical wiring, and electrical equipment usually produce low frequency EMFs, which are waves of invisible photons that surround any electrical device. The electromagnetic energy has various forms and can exhibit different biological effects. Although the low-frequency electric fields are not able to effectively penetrate living cells, lowfrequency magnetic fields get into them causing some deleterious effects (Blank \& Goodman, 1997).

The World Health Organization (WHO) maintains that no adverse health effects of EMFs are expected. However, the International Agency for Research on Cancer (IARC) has classified extremely low frequency EMF (specially the one that associated with high voltage power lines) as possible human carcinogen (Gangwar \& Chishti, 2014). Therefore, the biological effects of EMFs are still controversial. In humans, 
some epidemiological studies have revealed that exposure to EMFs increases the risk of diseases such as leukemia particularly among children (Kheifets et al., 2005). Nguyen et al. (2017) studied the effects of EMF on red blood cells and they reported that EMF induces rotating water dipoles caused disturbance of the membrane, initiating its deformation and result in an enhanced degree of membrane trafficking via a quasi-exocytosis process. The relationship between EMFs and various cancer types has also been demonstrated in other studies (Floderus et al., 1993; Dockerty et al., 1998 and Zhu et al., 2003). For example, EMFs increased the rate of chromosomal aberrations in human lymphocytes in vitro (Murphy et al., 1993).

Other model organisms including animals, plants and microorganisms have been employed to explore the possible potential effects of EMF on humans (Rajendra et al., 2005; Pinar et al., 2010; Rajendra et al., 2012 and Nguyen et al., 2017). Various studies revealed that several types of biological effects of EMFs were observed at cellular levels. It has been reported that EMF is associated with the suppression of mitotic activity (Murphy et al., 1993 and Rajendra et al., 2005), chromosomal aberrations including breakages (Garcia-Sagredo et al., 1991 and Hanafy et al., 2006), surface receptor redistribution and cytoskeleton reorganization (Cho et al., 1996), increase of oxygen free radicals (Jajte, 2000), DNA fragmentation (Diem et al., 2005), up-regulation of apoptotic genes (Zhao et al., 2007), and changes in intracellular $\mathrm{Ca}^{2+}$ concentration (Walleczek, 1992 and Rajendra et al., 2012). $\mathrm{Ca}^{2+}$ alterations have been speculated to mediate the EMFs effects in living cells. $\mathrm{Ca}^{2+}$ ion controls numerous biological processes such as signal transduction cascades, cell differentiation and proliferation (Cho et al., 1999). In addition, it is one of the key elements of the apoptotic pathway (Orrenius et al., 2003) and an increase in intracellular $\mathrm{Ca}^{2+}$ leads to cell death ( $\mathrm{Yu}$ et al., 2001 and Rajendra et al., 2012). Although, the mechanisms regulating the effects of EMF on plants are not completely understood, their effects on humans, animals and microorganisms have been vigorously studied (Pinar et al., 2010).

A wide range of physiological effects, altering fundamental biological processes and nutrient metabolism have been observed in plants as a result of the exposure to a high-voltage electric fields (Ynikiene \& Pozeliene, 1998 and Zhang et al., 1997). Particularly, electric field effects on the polarity of cells (Schnepf, 1986), transport of $\mathrm{Ca}^{2+}$ (Hepler \& Wayne, 1985), and distributions of auxin (Rathore \& Goldsworthy, 1985), mitosis and meiosis (Hanafy et al., 2006) have been examined. Several researchers have pointed out the effects of EMFs on plant growth and productivity (Xu et al., 2017). Therefore, to further our knowledge on the damaging effects of EMFs, this study investigated cytological, biochemical, and molecular changes occurring in faba bean seedlings exposed to different levels of EMFs. We also investigated the effect of household aluminum foil as a protector for the used plant system and whether EMF induced-mutations are transferable to the next generations or not.

\section{Material and Methods}

\section{Plant material}

Seeds of Vicia faba L. (cultivar Giza 402, a common broad bean cultivar grown in Egypt) were provided by the Agricultural Research Center (Giza, Egypt).

\section{EMF exposure and field experiment}

The exposure experiments were performed in three independent locations in the open agriculture filed (Seberbai, Tanta, Gharbia Governorate, at Latitude: $30^{\circ} 47^{\prime} 18^{\prime \prime} \mathrm{N}$, Longitude: $31^{\circ} 00^{\prime} 06^{\prime \prime} \mathrm{E}$, Elevation above sea level: $18 \mathrm{~m}$ ) in autumn 2014. Giza 402 seeds were germinated in disposable Petri-dishes $(55 \mathrm{~mm} \times 16 \mathrm{~mm})$ containing wood mulch for 10 days at three different distances $0 \mathrm{~m}$ (directly under the high-voltage transmission lines), $5 \mathrm{~m}$, and $10 \mathrm{~m}$ from the high-voltage transmission lines $(50 \mathrm{~Hz}, 66 \mathrm{kV})$ as demonstrated in Fig. 1A. The height of the closest transmission lines was $9 \mathrm{~m}$ above the ground, where Petri-dishes were placed (Fig. 1A). To explore the effect of EMF directions in space, Petri-dishes containing plant seeds were situated at different locations either right or left from the high-voltage transmission lines (Fig. 1B). The electromagnetic field intensities were measured at these points left and right from the transmission lines using Xploxer GLX device and 2 AXIS MAGNETIC FIELD sensor (PASCO, PS-2002, USA). The device measures the EMF in Gauss $(\mathrm{G})$ and EMF intensities were converted into MicroTesla $(\mu \mathrm{T})$.

Broad bean seeds were divided into six groups (30 seeds each) as follow:

Group 1 (control group): Giza 402 seeds were germinated $200 \mathrm{~m}$ away from the high-voltage 
transmission lines where $\mathrm{EMF}=0 \mu \mathrm{T}$.

Group 2: Seeds were germinated directly under high-voltage transmission lines $(0: 4051 \mu \mathrm{T})$.

Group 3: Seeds were germinated at $5 \mathrm{~m}$ left from the high-voltage transmission lines (5L:2312 $\mu \mathrm{T})$.

Group 4: Seeds were germinated at $5 \mathrm{~m}$ right from the high-voltage transmission lines (5R:2245 $\mu \mathrm{T})$.

Group 5: Seeds were germinated at $10 \mathrm{~m}$ left from the high-voltage transmission lines (10L: $783 \mu \mathrm{T})$.

Group 6: Seeds were germinated at $10 \mathrm{~m}$ right from the high-voltage transmission lines (10R: $720 \mu \mathrm{T})$.

For all groups, the treatment was done either with $(\mathrm{C})$ or without $(\mathrm{N})$ covering the seedlings with multipurpose household aluminum foil (thickness $=0.024 \mathrm{~mm}$, heavy-duty, Egypt), where the aluminum foil is supposed to act as a protective shield against the electromagnetic field as reported by Ott (1976). Seed samples were designated depending on the above-mentioned treatments, for example, seedlings grown at $5 \mathrm{~m}$ left of the highvoltage transmission lines without being covered with aluminum foil has been designated as $5 \mathrm{LN}$, while the covered ones were 5LC.

The possible inherited EMF effects were also evaluated by analyzing the first generation (M1) of the seedlings grown (zero generation; M0; Evans et al., 1984) in the proximity of the highvoltage power lines. In order to do that seeds of the M1 were germinated in the greenhouse of Botany Department, Tanta University in autumn 2015. For each analysis, three biological replicates consisting of 30 seedlings per treatment were used.

\section{Cytological preparations}

The cytotoxic effects of EMFs on secondary root tips of $V$. faba seedlings, germinated at different distances and locations from high-power transmission lines in M0 and M1 were examined using Feulgen squash technique according to Koa (1975). Ten slides were examined to evaluate the effects of EMFs on the mitotic index (MI), the percentage of normal and abnormal cells as well as chromosomal abnormalities using an electric microscope (Olympus CX40, Japan). At least 4000 cells for each distance point either right or left of high-power transmission lines were examined and cells with abnormalities were counted and the most representative ones were photographed using a digital microscopic camera (AmScope MU1000 10 MP, USA).

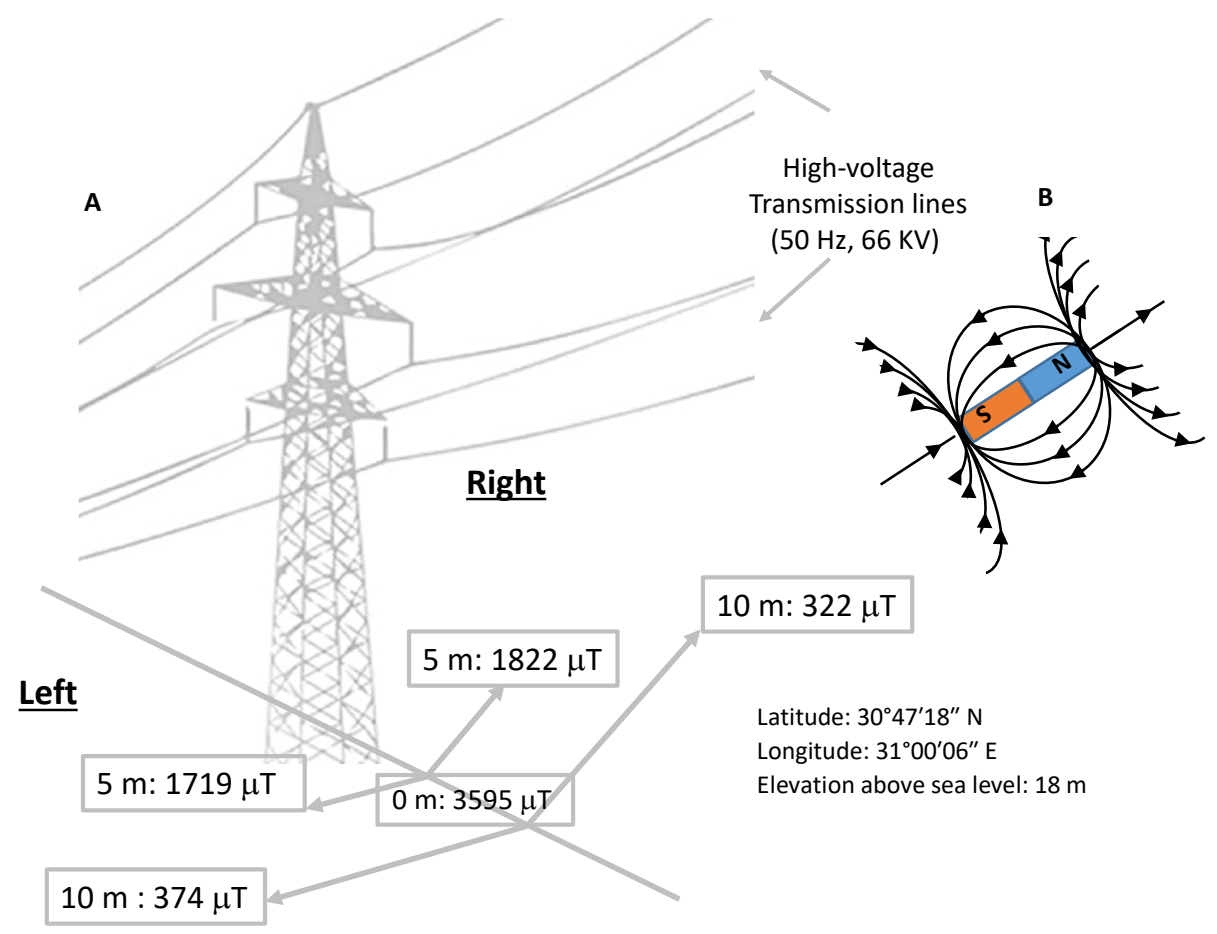

Fig. 1. Diagrammatic representation showing experiment design and EMFs exposure, A: The distances and locations of the plant samples, B: The direction of EMF. 
Calcium binding proteins electrophoresis and gel staining

For extraction of total proteins, $5 \mathrm{~g}$ of fresh leaf samples were homogenized in $1 \mathrm{ml}$ of $20 \%$ sucrose solution and centrifuged at $12000 \mathrm{rpm}$ for $5 \mathrm{~min}$ at $4^{\circ} \mathrm{C}$. The supernatants were transferred into new tubes and stored at $-20^{\circ} \mathrm{C}$. Non-reduced proteins electrophoresis was conducted according to ElShanshoury et al. (2005). $\mathrm{Ca}^{2+}$-binding protein bands were detected by using the method of Massaro \& Markert (1968). After electrophoresis, the gels were stained in a $50 \mathrm{ml}$ staining solution containing $0.05 \mathrm{~g}$ of Commassie Brilliant Blue $\mathrm{G}$, $7.5 \mathrm{~g}$ of Trichloroacetic acid (TCA), and $2.5 \mathrm{~g}$ of 5-sulfosalicylic acid at room temperature in dark. After the appearance of $\mathrm{Ca}^{2+}$-binding protein bands, the reaction was stopped by washing the gels three times with tap water and then fixed in ethanol:glacial acetic (1:9) solution. Finally, the gels were kept in the fixative solution for $24 \mathrm{~h}$ and then they were photographed.

\section{Calcium binding proteins gels analysis}

All gels used for calcium isozyme electrophoresis were scanned using GelDoc-2001 Bio-Rad system. Relative migration of each band was measured. The bands were scored as present (1) or absent (0).

Inter-simple sequence repeat (ISSR) analysis

Total genomic DNA was extracted from $2 \mathrm{~g}$ fresh leaves using CTAB method as described by Dehestani \& Tabar (2007). The DNA pellets were washed in $70 \%$ ethanol, air-dried, and re-dissolved in $100 \mu 1 \mathrm{TE}$ buffer. RNase and Proteinase K were applied to remove RNA and proteins, respectively from the DNA samples. Then, the concentration of DNA was measured using a Nanodrop (Thermo Fisher, USA). Five different primers were used in this experiment, the names, sequences, lengths and annealing temperatures were listed in Table 1. PCR reactions were implemented in a total volume of $30 \mu \mathrm{l}$ as described by Williams et al. (1990). For each reaction, the following reagent were mixed: $3 \mu 1$ PCR buffer $(10 \times), 3 \mu 1$ dNTPs $(2.5 \mathrm{mM}), 3 \mu \mathrm{l}$ $\mathrm{MgCl}_{2}(25 \mathrm{mM}), 2 \mu \mathrm{l}$ primer (10 pmol), $0.2 \mu \mathrm{l}(5 \mathrm{U} /$ $\mu \mathrm{l})$ Taq DNA polymerase, $2 \mu 1$ DNA template $(25$ $n g / \mu 1)$. The PCR amplifications were conducted in an automated Thermal Cycler (Techno TC512, UK) using the following cycling program: One cycle at $94^{\circ} \mathrm{C}$ for $4 \mathrm{~min}, 40$ cycles of $30 \mathrm{sec}$ at $94^{\circ} \mathrm{C}, 30 \mathrm{sec}$. at $44^{\circ} \mathrm{C}$ for primer $14 \mathrm{~A}$ and $38^{\circ} \mathrm{C}$ for the other primers, and $2 \mathrm{~min}$ at $72^{\circ} \mathrm{C}$. The final extension step was performed at $72^{\circ} \mathrm{C}$ for $10 \mathrm{~min}$. The reactions were held at $4^{\circ} \mathrm{C}$ forever. The PCR products were resolved on $1.5 \%$ agarose gels.

\section{ISSR gels analysis}

The gels of ISSRs were visualized and photographed using a gel documentation system (Biometra Bio Doc Analyze 2000, Germany) under UV transilluminator. The ISSR bands were scored as present (1) or absent (0), each of which was handled as an independent character in spite of its intensity. The percentage of polymorphism $(\%)$ was estimated by dividing the polymorphic bands by the total number of scored bands.

\section{Data analysis}

Mitotic Index (MI)

The mitotic index of each sample was calculated using the following equation:

Mitotic index $(\%)=$

\section{Number of cells in the mitotic phase Total number of cells}

Percentage of chromosomal abnormalities

The percentage of chromosomal abnormalities of each sample was calculated using the following equation: Chromosomal abnormalities $(\%)=$

Number of cells with abnormal chromosomes in the mitotic phase Total number of cells in the mitotic phase

TABLE 1. Names, sequences, lengths and annealing temperatures of ISSR primers used in this study.

\begin{tabular}{|c|c|c|c|}
\hline Primer name & Sequence (5’-3’) & Length (bp) & Annealing temp. \\
\hline $14 \mathrm{~A}$ & 5`-CTC TCT CTC TCT CTC TTG-3` & 18 & $44{ }^{\circ} \mathrm{C}$ \\
\hline 44B & 5'-СТC ТСТ СТC ТСТ CTC TTG-3` & 18 & $38^{\circ} \mathrm{C}$ \\
\hline HB-09 & 5 '-GTG TGT GTG TGT GC-3’ & 14 & $38^{\circ} \mathrm{C}$ \\
\hline HB-10 & $5^{\prime}$-GAG AGA GAG AGA CC-3' & 14 & $38^{\circ} \mathrm{C}$ \\
\hline HB-15 & 5'-GTG GTG GTG GC-3' & 11 & $38^{\circ} \mathrm{C}$ \\
\hline
\end{tabular}




\section{Clustering analysis}

Cluster analysis was done using NTSYSPc software ver. 2.1 (Rohlf, 2000). The Jaccard correlation coefficient between the treated samples and control for M0 and M1 was calculated to determine the similarity among them, using the combined data from biochemical markers (calcium binding proteins) and genetic molecular markers derived from ISSRs as well.

\section{Statistical analysis}

All experiments were done using at least three biological replicates and Tukey's post-hoc test for multiple variance was utilized to compare differences among samples (Zar, 1999). The statistical analyses were performed using SPSS software ver. 15.0 (SPSS $^{\circledR}$ software, http://www. spss.com).

\section{Results}

\section{Cellular effects of EMFs}

The mitotic index (MI) of zero generation (M0) individuals, which were grown under the highvoltage power lines at different distances $(0,5$, and $10 \mathrm{~m}$ ) and different locations either left or right are presented in Table 2. There was no significant variation among mitotic indices of EMFs exposed seedlings at different distances, while significant differences among means of chromosomal abnormalities were observed (Table 2). The results revealed that the untreated root tips (control sample both covered and non-covered) have the lowest percentage of chromosomal abnormalities, while the highest percentage of chromosomal abnormalities were found at zero point (directly under the transmission lines). There was a gradual reduction in chromosomal abnormalities percentage with increasing distances from the high-voltage power lines. At zero distance from high-voltage transmission lines, the percentage of chromosomal abnormalities of non-covered $(0 \mathrm{~N})$ and covered $(0 \mathrm{C})$ seedlings were $20.20 \%$ and $20.19 \%$, respectively. The gradual reduction in the percentage of chromosomal abnormalities was observed with increasing distance from the transmission lines until $9.7 \%$ at $10 \mathrm{~m}$ left noncovered (10LN), 9.6\% at covered $10 \mathrm{~m}$ left (10LC), $11.3 \%$ at covered $10 \mathrm{~m}$ right (10RC) and $10.1 \%$ at $10 \mathrm{~m}$ right non-covered (10RN). Meanwhile, there was a negligible relationship between covered and non-covered seedling roots, as the chromosomal abnormalities at $5 \mathrm{~m}$ left reduced from $15.64 \%$ in non-covered $(5 \mathrm{LN})$ seedling roots to $14.47 \%$ in covered seedling roots $(5 \mathrm{LC})$ and at $5 \mathrm{~m}$ right reduced from $17.18 \%$ in non-covered $(5 \mathrm{RN})$ samples to $15.15 \%$ in covered (5RC) samples.

High percentage of micronuclei was observed in the roots of seedlings $(0 \mathrm{C}$ and $0 \mathrm{~N})$, which were germinated directly under the high-voltage transmission lines. In addition, micronuclei percentage was higher in $0 \mathrm{~N}$ seedlings $(33.1 \%)$ compared to $0 \mathrm{C}(16 \%)$. To explore the inherited effects in the first generation (M1), the seeds of the non-covered seedlings were germinated at area free from any EMFs sources $(0 \mu \mathrm{T})$. After germination, the secondary root tips were collected for cytological analysis to evaluate the mitotic indices and chromosomal abnormalities. There were no significant differences in mitotic index among the tested samples (Table 3). In addition, no significant variation in chromosomal abnormalities of M1 plants was found in comparison with control.

In order to investigate the possible effects of EMFs exposure on the chromosome structure, the Feulgen squash technique employed in zero (M0) generation. The results indicated that EMFs exposure potentially induced c-metaphases, $\mathrm{c}$-anaphases, disturbed prophases, sticky prophases, sticky metaphases, bi-nucleated cells, lagging chromosomes, chromosome bridges, oblique orientation of division and micro nuclei (Fig. 2).

The root tips of control covered (CC) and control non-covered $(\mathrm{CN})$ seedlings showed the lowest percentage of chromosomal abnormalities, while the highest percentage of chromosomal abnormalities was found at zero distance of both covered $(0 \mathrm{C})$ and non-covered $(0 \mathrm{~N})$ seedlings. Also, there was a gradual reduction in the percentage of chromosomal abnormalities with increasing distances from the high-voltage power lines (Fig. 3). Roots directly underneath the high-voltage power lines ( 0 distance) for both covered $(0 \mathrm{C})$ and noncovered $(0 \mathrm{~N})$ showed a unique micronuclei cells, which could be used as a cytological marker for the strong effect of EMF at cellular level. Moreover, binucleate cells were also very common among the different types of chromosomal aberrations and only detected in EMFs exposed seedlings. A change in the orientation of cell division poles (oblique cell division) recognized at $5 \mathrm{~m}$ a side of high-voltage power lines. In conclusion, it is apparent that binucleate and micronuclei cells may be used as a cytological marker for EMFs. 
TABLE 2. Effects of EMFs on mitotic index (MI) and average of chromosomal abnormalities (ACA) of Vicia faba L. secondary root tips of zero generation (M0) at different distances and locations from the high-voltage power lines.

\begin{tabular}{lcccc}
\hline Treatment & Total Average Cells Count & Mitotic Cells Average & MI & ACA \\
\hline CC & 4083 & 152 & $3.66 \%$ & $4.60 \%^{\mathrm{f}}$ \\
$\mathrm{CN}$ & 4071 & 140 & $3.43 \%$ & $4.28 \%^{\mathrm{f}}$ \\
$0 \mathrm{C}$ & 4200 & 203 & $4.83 \%$ & $20.19 \%^{\mathrm{a}}$ \\
$0 \mathrm{~N}$ & 4033 & 198 & $4.90 \%$ & $20.2 \%^{\mathrm{a}}$ \\
$5 \mathrm{LC}$ & 4150 & 221 & $5.32 \%$ & $14.47 \%^{\mathrm{b}}$ \\
$5 \mathrm{LN}$ & 4250 & 179 & $4.21 \%$ & $15.64 \%^{\mathrm{b}}$ \\
$10 \mathrm{LC}$ & 4028 & 176 & $4.36 \%$ & $9.65 \%^{\mathrm{ed}}$ \\
$10 \mathrm{LN}$ & 4063 & 216 & $5.31 \%$ & $9.72 \%^{\mathrm{ed}}$ \\
$5 \mathrm{RC}$ & 4050 & 132 & $3.25 \%$ & $15.15 \%^{\mathrm{b}}$ \\
$5 \mathrm{RN}$ & 4133 & 192 & $4.64 \%$ & $17.18 \%^{\mathrm{bc}}$ \\
$10 \mathrm{RC}$ & 4150 & 212 & $5.32 \%$ & $11.32 \%^{\mathrm{d}}$ \\
$10 \mathrm{RN}$ & 4040 & 189 & $4.67 \%$ & $10.58 \%^{\mathrm{d}}$ \\
\hline
\end{tabular}

-CC (control covered with aluminum foil), $\mathbf{C N}$ (control non-covered), $\mathbf{0 C}$ (seedlings at distance $0 \mathrm{~m}$ from high-voltage power lines and covered with aluminum foil), $\mathbf{0 N}$ (seedlings at distance $0 \mathrm{~m}$ from high-voltage power lines and non-covered with aluminum foil), $5 \mathrm{LC}$ (seedlings at distance $5 \mathrm{~m}$ left to 0 point from high-voltage power lines and covered with aluminum foil), $\mathbf{5 L N}$ (seedlings at distance $5 \mathrm{~m}$ left to 0 point from high-voltage power lines and non-covered), 10LC (seedlings at distance $10 \mathrm{~m}$ left to 0 point from high-voltage power lines and covered with aluminum foil), 10LN (seedlings at distance $10 \mathrm{~m}$ left to 0 point from high-voltage power lines and non-covered), 5RC (seedlings at distance $5 \mathrm{~m}$ right to 0 point from high-voltage power lines and covered with aluminum foil), $\mathbf{5 R N}$ (seedlings at distance $5 \mathrm{~m}$ right to 0 point from high-voltage power lines and non-covered), 10RC (seedlings at distance $10 \mathrm{~m}$ right to 0 point from high-voltage power lines and covered with aluminum foil), 10RN (seedlings at distance $10 \mathrm{~m}$ right to 0 point from high-voltage power lines and non-covered).

-Significant difference $(\mathrm{P} \leq 0.01)$ is indicated by different letters.

TABLE 3: Effects of EMFs on mitotic index (MI) and average of chromosomal abnormalities (ACA) of Vicia faba L. secondary root tips of first generation (M1) at different distances from the high-voltage power lines.

\begin{tabular}{lcc}
\hline Treatment & MI & ACA \\
\hline CC & $4.18 \%$ & $3.48 \%$ \\
$0 \mathrm{~N}$ & $4.42 \%$ & $4.50 \%$ \\
$5 \mathrm{LN}$ & $4.59 \%$ & $4.47 \%$ \\
$10 \mathrm{LN}$ & $4.50 \%$ & $4.59 \%$ \\
$5 \mathrm{RN}$ & $4.63 \%$ & $4.63 \%$ \\
$10 \mathrm{RN}$ & $4.47 \%$ & $4.42 \%$ \\
\hline
\end{tabular}

$\mathbf{C N}$ (control non-covered), $\mathbf{0 N}$ (seedlings at distance $0 \mathrm{~m}$ from the high-voltage power lines and non-covered with aluminum foil), $\mathbf{5} \mathbf{L N}$ (seedlings at distance $5 \mathrm{~m}$ left to 0 point from high-voltage power lines and non-covered), 10LN (seedlings at distance $10 \mathrm{~m}$ left to 0 point from high-voltage lines and non-covered), $5 \mathrm{RN}$ (seedlings at distance $5 \mathrm{~m}$ right to 0 point from high-voltage power lines and noncovered), 10RN (seedling at distance $10 \mathrm{~m}$ right to 0 point from high-voltage power lines and non-covered).

In M1 generation, some chromosomal abnormalities, included c-metaphases, c-anaphases, disturbed prophases, sticky chromosomes, lagging chromosomes and chromosome bridges, were rarely observed indicating that the chromosomal repair mechanism in faba bean is efficient to fix the most of the chromosomal abnormalities induced by EMFs through successive generations.

\section{Effects of EMFs on calcium binding proteins}

Calcium plays an important role in cell division and other metabolic processes. Therefore, calcium binding proteins (CBPs) were studied in order to investigate the potential effect of EMFs on cell division and bi-nucleated cells formation. The polyacrylamide gel electrophoresis (PAGE) of calcium binding proteins exhibited five different loci (CBP1, CBP2, CBP3, CBP4, and CBP5) 
as represented in Fig. 4. In M0, the CBP1 locus showed three clear bands. The upper CBP1 band was present only in covered treatments $(0 \mathrm{C}, 5 \mathrm{LC}$, and 10LC) and control covered seedlings (CC), while disappeared in the treatments of $10 \mathrm{RN}$, $10 \mathrm{RC}, 5 \mathrm{RN}, 5 \mathrm{RC}, 10 \mathrm{LN}, 5 \mathrm{LN}, 0 \mathrm{~N}$, and control non-covered seedlings (CN). However, 5RC and 10RC did not show this band. The middle band of CBP1 was common in all treatments and in control seedlings (covered and non-covered) except for 10RN (Fig. 4, black arrow). The CBP1 lower most band was only recognized in the treatment $10 \mathrm{LN}$. In contrast to M0, M1 seedlings showed two bands only for the locus CBP1. The locus CBP2 consists of only one protein band, which was present in all treatment groups and controls except for M15LN. Similarly, CBP4 consists of one protein
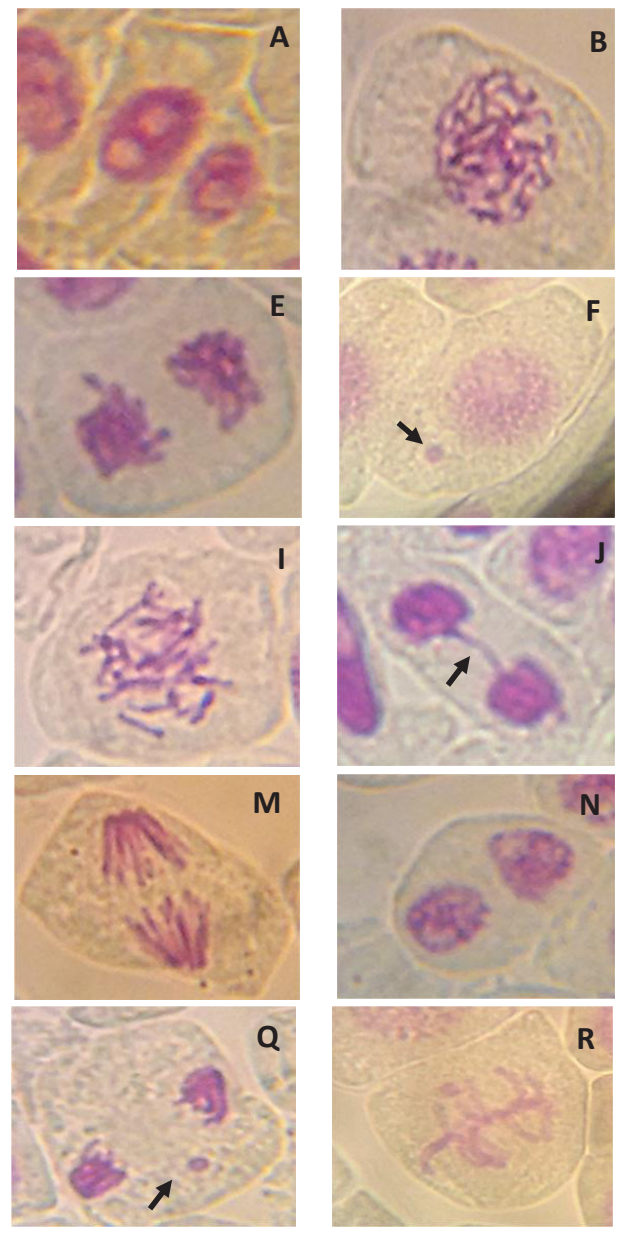

Fig. 2. Different types of chromosomal abnormalities induced by electromagnetic fields (EMF) from high voltage power lines in Vicia faba L. secondary root tips. A: Normal interphase, B: Normal prophase, C: Normal metaphase, D: Normal anaphase, E: Normal telophase, F: Micronucleus in interphase, G: Sticky prophase, H: C-metaphase, I: C-anaphase, J: Bridge in telophase, K: Disturbed prophase, L: Sticky metaphase, M: Oblique cell division, N: Binucleate cell, O: Lagging chromosome in metaphase, P: Bridge anaphase, Q: Micronucleus in telophase, R: Disturbed metaphase. 


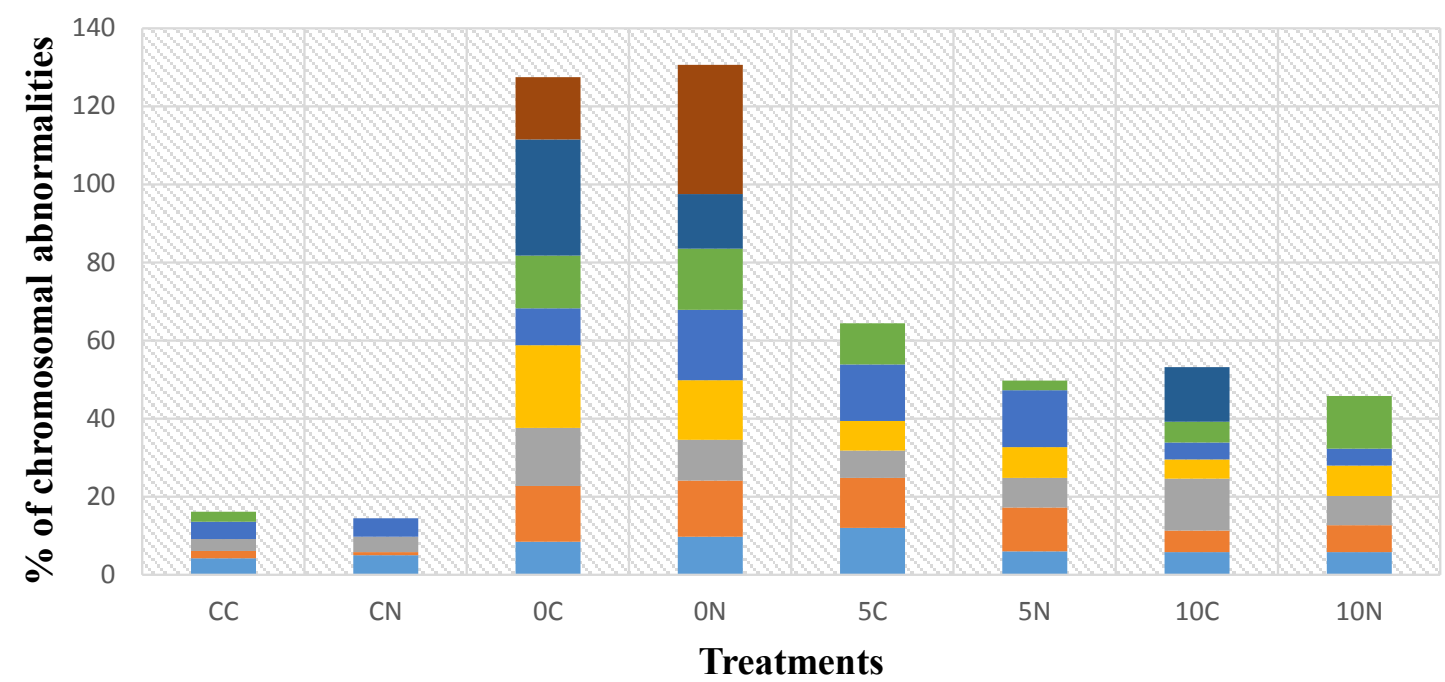

Fig. 3. Effects of electromagnetic filed (EMF) on composition of chromosomal abnormalities of Vicia faba L. secondary root tips of zero generation (M0) grown at different distance from the high-power tension lines. Control root covered with aluminum foil (CC), Control root not covered with aluminum foil (CN), roots grown directly underneath the high-power tension lines covered with aluminum foil $(0 \mathrm{C})$, roots grown directly underneath the high-power tension lines not covered $(0 \mathrm{~N})$, roots grown at $5 \mathrm{~m}$ a side of the highpower tension lines covered with aluminum foil $(5 \mathrm{C})$, roots grown at $10 \mathrm{~m}$ a side of the high-power tension lines covered with aluminum foil $(10 \mathrm{C})$, roots grown at $10 \mathrm{~m}$ a side of the high-power tension lines covered with aluminum foil (10C).

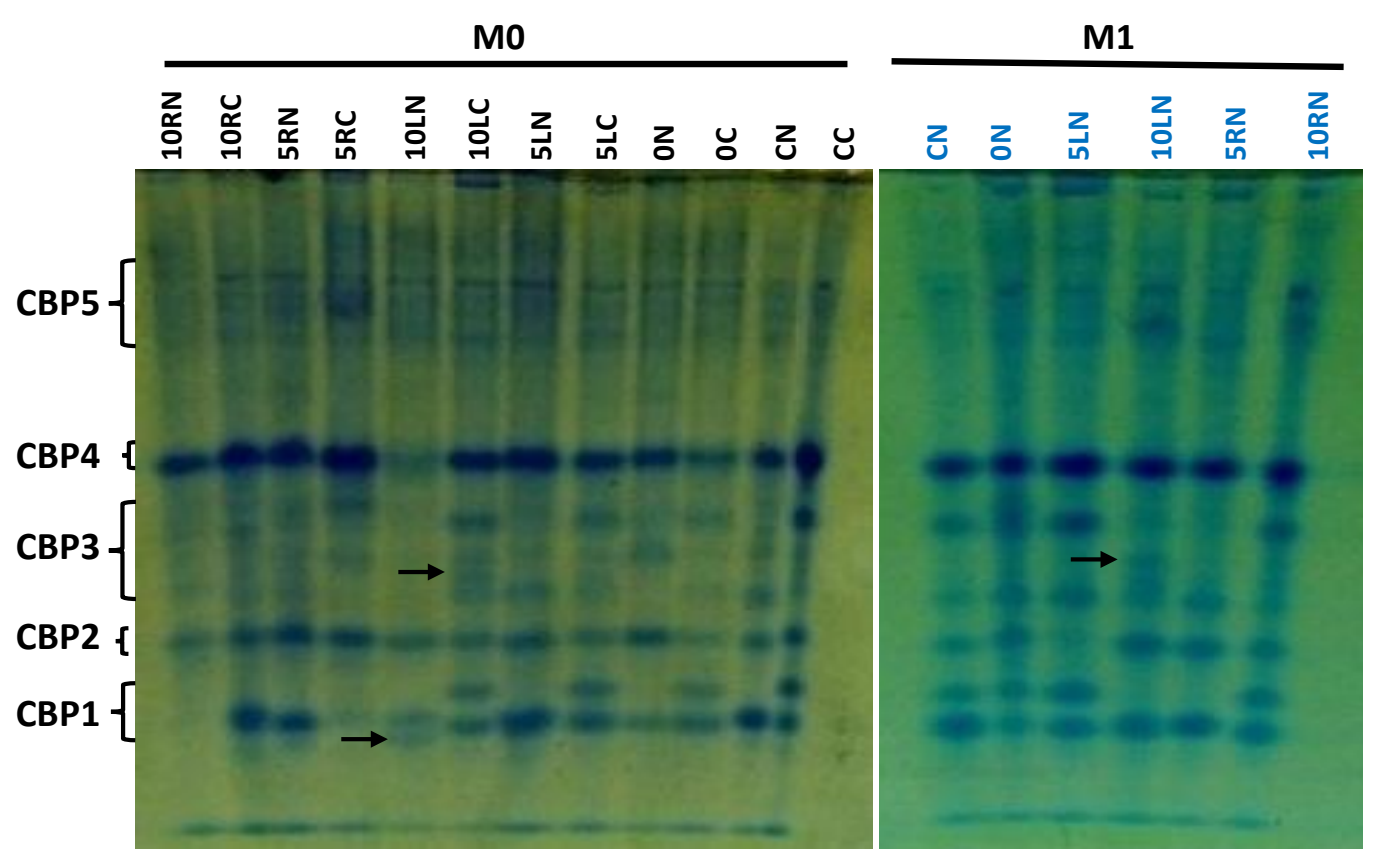

Fig. 4. Effects of electromagnetic filed (EMF) on seedling locus constitution of $\mathrm{Ca}^{2+}$-binding protein (CBP) isoforms at different distances $(0,5$ and $10 \mathrm{~m})$ on the left and right side of high power tension lines of zero generation (M0). The inherited effects of electromagnetic filed (EMF) on the CBP loci of pooled non-covered seedling (from right and left sides of lines) during first generation (M1, blue color). Arrows indicate unique banding patterns. 
Effects of EMFs on ISSR-based genetic variation

In order to examine the genetic variation and designate marker bands among EMFs exposed seedlings, ISSR technique was applied. Among the five used ISSR primers (Table 1) only primer 14B did not amplify any PCR products. The results of other four ISSR primers showed that 14 highly reproducible ISSR bands were amplified. Their molecular size ranged from $500 \mathrm{bp}$ to 1000 bp. The number of polymorphic bands were 9 out of the 14 , while the remaining 4 bands were 3 monomorphic bands and only one unique band (Table 4). The average of polymorphic bands were 2.25 bands per primer.

As shown in Fig. 5, primer 44B gave three bands with molecular size ranged from $600 \mathrm{bp}$ to $850 \mathrm{bp}$, of which two bands were monomorphic and 1 band was polymorphic. One polymorphic band (850 bp) was amplified in all samples except M0-10RN, M0-5RC, M0-5LN, M0-5LC, M0-0N, M0-0C, M0-CN, and M1-0N. Primers HB-09 and HB-10 showed three polymorphic bands. One unique ISSR band (750 bp; Fig. 5, black arrow) was amplified with primer HB-10 in M0-10RC. In contrast to the three previous primers, the primer HB-15 showed one monomorphic band and three polymorphic bands. The polymorphism percent was calculated based on ISSR data and showed that primers HB-09 and HB-15 produced the highest polymorphism $100 \%$ and $75 \%$, respectively, while primer 44B and primer HB10 gave the lowest polymorphism $33 \%$ and $66 \%$, respectively.

\section{Clustering analysis}

In order to determine whether EMFs-induced variation will be recovered or not, we preformed cluster analysis using the combined data from calcium binding proteins and ISSR banding patterns. The genetic distance (according to Jaccard coefficient) ranged from minimum value 0.56 to maximum value 0.86 . As shown in Fig. 6, the samples were clustered in two main groups; the first cluster (G1) included M0-10RN and the second cluster (G2) was divided into two subclusters. The first sub-cluster (I) included M010RC, M0-5RC, and M0-CN, while the second sub-cluster (II) divided into three sub-clusters the first sub-clusters (A) included M0-5RN, M0-5LN, M1-10LN, M0-10LN, and M0-10LC. Meanwhile, the second sub-cluster (B) included M0-5LC, M0-0C, M0-0N, M0-CC, M1-CN, M1-5LN, and $\mathrm{M} 1-0 \mathrm{~N}$. The third sub-cluster (C) included M1-5RN and M1-10RN. These results indicated that samples of the first generation (M1) were grouped together based on their genetic distance except M1-10LN treatment has clustered with M0 treatments.

TABLE 4. Effect of EMFs on the number of monomorphic and polymorphic ISSR bands. The total number of bands and percentage of polymorphism produced by four primers (44B, HB-09, HB-10 and HB-15) in Vicia faba L. seedlings germinated at different distances from EMFs in zero generation (M0).

Primers

\begin{tabular}{lcccc}
\hline Type of bands & 44B & HB-09 & HB-10 & HB-15 \\
No. Monomorphic bands & 2 & 0 & 1 & 1 \\
& & & & \\
No. unique bands & 0 & 0 & 1 & 3 \\
No. polymorphic bands & 1 & 3 & 2 & 4 \\
Total number of bands & 3 & 3 & 4 & $75 \%$ \\
Polymorphism $(\%)$ & $33 \%$ & $100 \%$ & $66 \%$ & \\
\hline
\end{tabular}




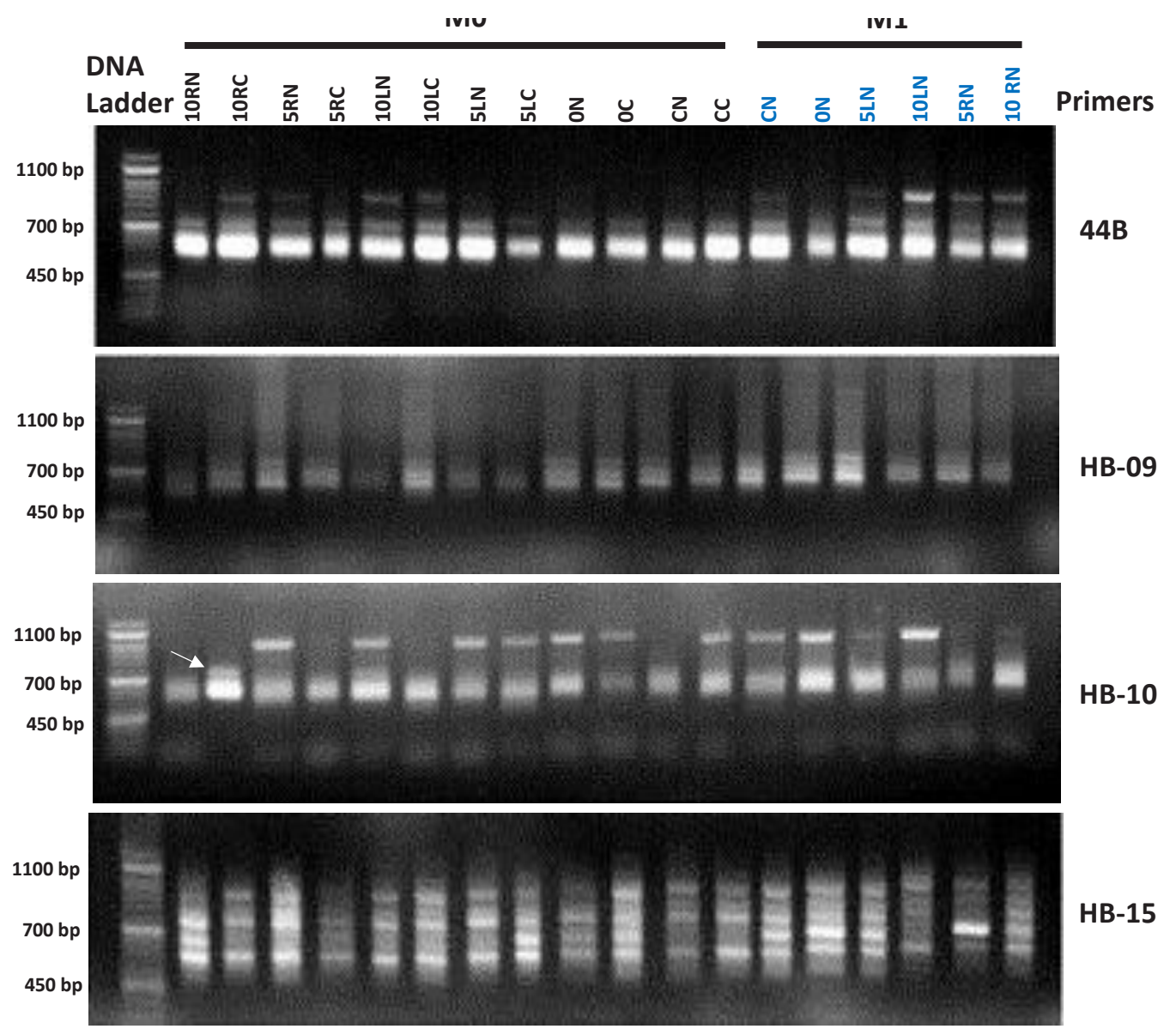

Fig. 5. Profiles of ISSR primers (44B, HB-09, HB-10, and HB-15) of Vicia faba L. show the effects of EMFs on DNA of seedlings germinated at different distances $(0,5$ and $10 \mathrm{~m})$ on the left and right side of high power tension lines of zero generation (M0). The inherited effects of electromagnetic filed (EMF) on the DNA of pooled non-covered seedling (from right and left sides of lines) during first generation (M1, blue color).

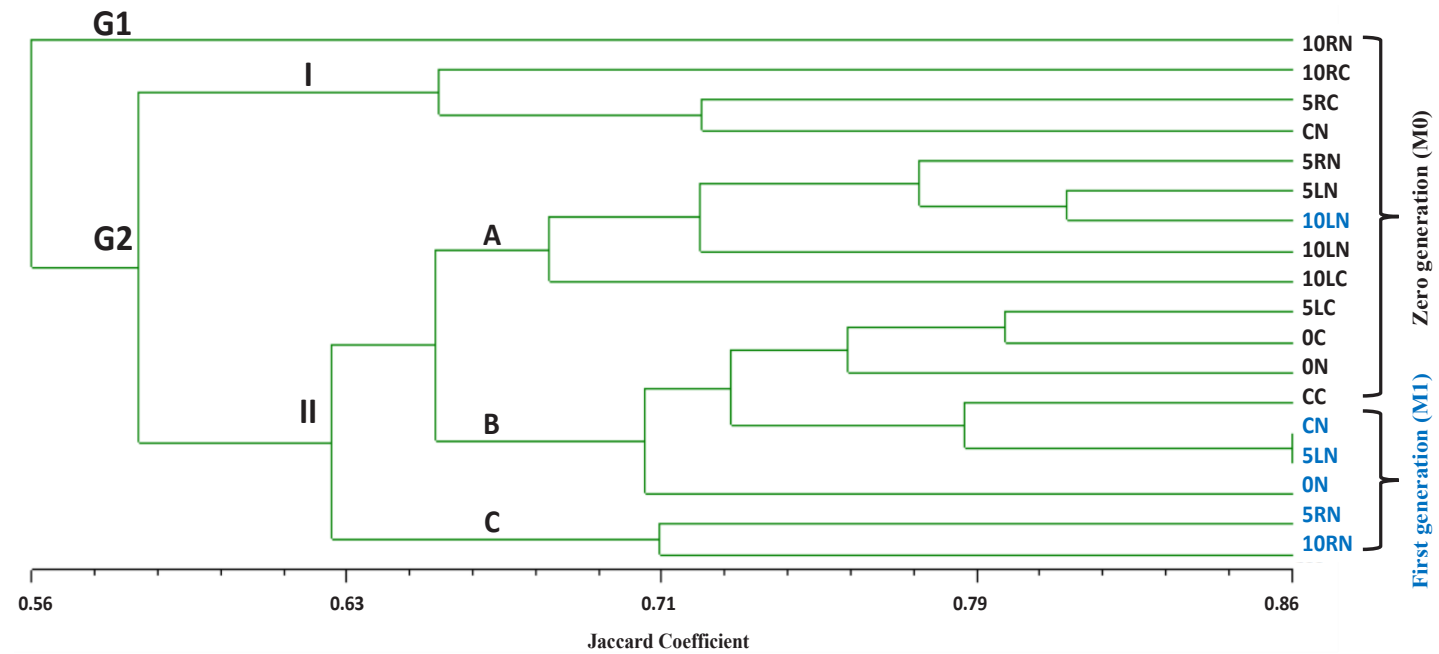

Fig. 6. Cluster analysis of Vicia faba L. seedlings germinated at different distances from high-voltage lines using combined data of calcium binding proteins and ISSR molecular markers. Zero generation (M0) 10RN, 10RC, 5RC, CN, 5RN, 5LN, 10LN, 10LC, 5LC, 0C, 0N, and CC (black color). First generation (M1) CN, $5 \mathrm{LN}, 0 \mathrm{~N}, 5 \mathrm{RN}, 10 \mathrm{RN}$, and 10LN (blue color). 


\section{Discussion}

The electromagnetic fields (EMFs) include two different field types. The first is the electric field, which is formed due to the difference in voltage. The second is the magnetic field, which results from the flow of electric current. This magnetic field consists of photons that travel in waves-like pattern. In particular, these magnetic fields have more damaging results due to their ability to penetrate the living tissues (Goldsworthy, 2006). EMFs are produced naturally by the earth whereas many sources of artificial EMFs are produced by telecommunication, microwaves, electric-wires, TVs, high-voltage power lines, and computers. The International Agency for Research on Cancer (IARC) has classified the extremely low frequency EMFs that produced by high-voltage power lines are plausible human carcinogens (Gangwar \& Chishti, 2014). It has been reported that EMFs that produced by high-power lines are recognized by their biological effects (Rajendra et al., 2005; Hanafy et al., 2006; Goldsworthy, 2006 and Rajendra et al., 2012). In the current study, we explored the impacts of EMFs in $V$. $f a b a$ as a model plant system at cytological, biochemical and molecular levels. The effect of EMFs depends on the energy absorbed by a biological organism and on how the energy is delivered in space and time. Frequency, intensity, exposure duration, and the number of exposure events can affect the response, and these factors can interact with each other to produce different effects (Goldsworthy, 2006). For these reasons, we designed this experiment by placing faba bean germinating seeds at different locations (right and left) and at different distance from the source of EMFs.

Cytological studies revealed that EMFs have a strong cytomutagenic effects on chromosomes structure of secondary roots cells of the faba bean seedlings. In zero (M0) generation, the percentage of abnormalities increased gradually with decreasing distance from the high-voltage power lines (Fig. 3). The lowest percentages of abnormalities were found in control seedlings that were germinated $200 \mathrm{~m}$ away from the EMFs source (high-voltage transmission lines), while the highest percentages of abnormalities $(20.20 \%)$ were found at zero distance (noncovered seedlings, directly germinated under the high-voltage transmission lines) and at zero distance (covered seedlings, directly germinated under the high-voltage transmission lines) as the percentage of abnormalities was $20.19 \%$ (Tables 2 and 3). Several types of abnormalities were found in response to EMFs-exposure like c-metaphases, c-anaphases, disturbed prophases, sticky chromosomes, bi-nucleated cells, lagging chromosomes, chromosome bridges, oblique chromosomes, and micronuclei (Fig. 2). The increase in the percentages of such chromosomal aberrations is in agreement with the findings of several studies (Rajendra et al., 2005; Hanafy et al., 2006 and Shabrangi et al., 2011). In addition, no significant change in mitotic index of the seedlings exposed to different EMF intensities. This result is consistent with Rajendra et al. (2005), who found no significant difference between mitotic index of the seedlings exposed to total exposure $(5,50$, and $100 \mu \mathrm{T})$ and delayed exposure (5 and $50 \mu \mathrm{T}$ ) compared to control. Quite number of studies have shown that exposure to extremely low frequency EMF such as the one resulted from the high-voltage power lines could lead to DNA damage. It has been reported that exposure to EMF may promote the Fenton reaction to produce free radicals, which attack cells of a biological system (Phillips et al., 2009). Fenton reaction is a process catalyzed by iron in which hydrogen peroxide, a product of oxidative respiration in the mitochondria, is converted into hydroxyl free radicals, which are very potent and cytotoxic molecules. These free radicals attack some macromolecules in cells such as DNA, protein, and membrane lipids. Many reviews indicated that EMF enhances free radical production in cells (Lai \& Singh, 1996; Oral et al., 2006 and Simkó, 2007). These lead to anticipate that in the secondary roots of faba bean exposed to low frequency EMF, free radicals were produced and attacked DNA on the chromosomes resulting in chromosomal abnormalities (Goldsworthy, 2006 and Hanafy et al., 2006). This speculation is very much aligning with our findings that indicated high micronuclei percentage and variation in ISSR profiles (Fig. 5) observed in faba bean seedlings directly germinated under the transmission lines. Moreover, this result is similar to what was found by Hanafy et al. (2006) on wheat plants exposed to low frequency electric fields. Micronuclei have been reported to originate from lagging chromosomes and chromosomal fragments existed in mitotic stage (Promila et al., 1991; Ahmad \& Yasmin, 1992; Hanafy et al., 2006 and Zeidali et al., 2017).

The abundance of binucleate cells and failure 
in cytokinesis in our study indicated that these abnormalities might be cytological markers that could be used to detect the effect of EMF exposure till $10 \mathrm{~m}$ a side of high-voltage power lines. Similarly, such abnormalities were reported as strong cytological characteristics for formation of cancerous cells in human (Bonassi, 2006 and Timms \& Horwitz, 2010). Also, we have reported that the production of c-metaphase/ anaphase chromosomes, disturbed prophases, and oblique chromosomes were significant in EMFsexposed seedlings. It was found that formation of these abnormalities could be due to damage of mitotic spindles caused by EMFs-induced free radicals (Aksoy et al., 2010). In another study with agreement with us, Ha (2001) has been documented that EMF elevates intracellular calcium, which likely bound to the surfaces of cell membranes and consequently resulting in cytokinesis failure and the formation of binucleate cell.

To ensure that the effects of EMFs were not permanent, the roots of next generation of treated plants were examined. We found that the average chromosomal abnormalities detected in the offspring (M1) of the treated plants were nonsignificant and many chromosomal abnormalities were not observed in roots of M1 seedlings particularly bi-nucleated cells, oblique chromosomes, and micronuclei were completely absent indicating that EMF effect was temporal and did not cause any permanent mutations in the treated plants. In addition, this effect was not inherited to the following generation. This may be due to energy transferred by $50 / 60-\mathrm{Hz}-\mathrm{EMFs}$ is not sufficient to directly damage DNA or the exposure time is not enough to cause permanent mutations (Sander et al., 1982). However, the EMF-generated free radicals affected DNA structure resulting in chromosomal aberrations or leading to cytotoxic effects (Piacentini et al., 2001), which might have been recovered in the offspring of M0 generation.

Calcium binding proteins (CBP-isoforms), which are proteins that participate in calcium cell signaling pathways by binding to $\mathrm{Ca}^{2+}$, CBP profiles showed random and inconsistent distribution of the different alleles due to EMF exposure, which was similar to that of ISSR profiles. These results are in agreement with the findings of Hanafy et al. (2006) and Shabrangi et al. (2011). The disturbance in $\mathrm{Ca}^{2+}$ binding isozymes may due to the effect of EMFs on intra-cellular $\mathrm{Ca}^{2+}$ deposition, which increased in response to the effect of EMFs (Pinar et al., 2010). Moreover, $50 / 60 \mathrm{~Hz}$ magnetic fields altered the movement of $\mathrm{Ca}^{2+}$ ions through channels in the cell membrane surfaces, disturb the ionic current in the transmembrane channel and membrane surface of the cells of the germinating Vicia faba seedlings resulting in changes in activities of housekeeping enzymes (Rajendra et al., 2005) and in membrane permeability in Glycine $\max$ (Arbabian et al., 2009). Recently, it has been reported that EMFs seem to target the signaling system of plant cells involving $\mathrm{Ca}^{2+}$ ions. This interference with the role of $\mathrm{Ca}^{2+}$ in cell signaling mechanisms is strongly suspected to be a key effect of magnetic fields on organism (Belyavskaya, 2004 and Sudsiri et al., 2017). The exposure of germinating Vicia faba seedlings to magnetic field up to $100 \mu \mathrm{T}$ did not produce any permanent biochemical changes in germinating seedlings as described by Rajendra et al. (2005), which was similar to the results obtained in our study. This may be explained that Vicia faba germinating seedlings have high adaptability to EMF stress (Rajendra et al., 2005).

Generally, the cluster analysis based on calcium binding proteins combined with ISSR markers showed that the first-generation treatments (M1) are clustered together except M1-10LN, seeds germinated directly under the high-voltage power lines of zero generation (M0) covered and non-covered $(0 \mathrm{C}$ and $0 \mathrm{~N})$ clustered together. In addition, treatments of each generation (M0 or M1) except M1-10LN clustered together. Moreover, the treatments of the same distance from the high-voltage power lines were clustered together, which was in agreement with the findings of McDonald \& Paulsen (1997) and EL-Bakatoushi (2010), which indicating that most of the deleterious effects of EMFs have been recovered in the offspring of M0 generation. Moreover, no significant variation between covered samples and non-covered samples has been detected indicating that the used aluminum sheets are not effective in reducing the magnetic fields generated from high-voltage transmission lines indicating that magnetic waves penetrated the aluminum sheets of the covered Vicia faba seedlings as reported by Ott (1976).

\section{Conclusions}

This study indicated that EMFs have a 
cytomutagenic effect on the secondary root tips of faba bean seedlings as they induced many types of chromosomal abnormalities. Some of these abnormalities, such as bi-nucleated cells are abundant and considered as strong cytological markers for cancer in human. In addition, EMFs disturbed calcium binding protein isoforms, which play important role in calcium metabolism. ISSR analysis showed that EMFs induced genetic variation in broad bean seedlings in the form of unique bands compared to control. It was found that the effect of EMFs decreased with increasing the distance from the high-voltage power lines and 200 meters away from the high-voltage power lines, where the germinating control seedlings were placed, is considered to be a safe distance. The effect of EMFs has not inherited in the upcoming generations and was reverted to normal, which is due to adaptability to EMFs stress and the powerful DNA repair mechanisms in faba bean. It seems that EMFs have a mutagenic effect on living organisms and long exposure must be avoided. Lastly, using plant system to study the potential effects of environmental hazardous is an elegant tool to uncover the possible effects of that hazardous on the human because plants are inexpensive, sensitive, and easy to handle.

Acknowledgement: Authors would like to thank Dr. Yasser Abdo, Physics Department, Faculty of Science, Tanta University for providing the device for measuring EMF intensities.

\section{References}

Ahmad, S. and Yasmin, R. (1992) Effects of methyl parationand tri-miltox on the mitosis of Allium cepa. Cytologia, 57, 155-160.

Aksoy, H. Unal, F. and Ozcan, S. (2010) Genotoxic effects of electromagnetic fields from high voltage power lines on some plants. International Journal of Environmental Research, 4(4), 595-606.

Arbabian, S., Majd, A. and Salaripour, S. (2011) The effects of electromagnetic field (EMF) on vegetative organs, pollen development, pollen germination and pollen tube growth of Glycine max L. Journal of Cell and Tissue, 1(1), 35-42.

Belyavskaya, N.A. (2004) Biological effects due to weak magnetic field on plants. Advanced Space Research, 34, 1566-1574.
Blank, M. and Goodman, R. (1997) Do electromagnetic fields interact directly with DNA? Bioelectromagnetics, 18, 111-115.

Bonassi, S. (2006) Predictivity of micronuclei in cancer risk and chromosomal aberrations for quantitative analysis for cancer risk. Paper resented at the O-046 ${ }^{\text {th }}$. In: From Genes to Molecular Epidemiology. $36^{\text {th }}$ Annual Meeting ofthe EEMS, Prague.

Cho, M.R., Thatte, H.S., Lee, R.C. and Golan, D.E. (1996) Reorganization of microfilament structure induced by AC electric fields. Federation of American Societies for Experimental Biology Journal, 10, 1552-1558.

Cho, M.R., Thatte, H.S., Silvia, M.T. and Golan, D.E. (1999) Transmembrane calcium influx induced by AC electric fields. Federation of American Societies for Experimental Biology Journal, 13, 677-683.

Dehestani, A. and Tabar, S.K. (2007) A rapid efficient method for DNA extraction from plants with high levels of secondary metabolites. Asian Journal of Plant Sciences, 6, 977-981.

Diem, E., Schwarz, C., Aldkofer, F., Jahn, O. and Rudiger, H. (2005) Non-thermal DNA breakage by mobile phone radiation $(1800 \mathrm{MHz})$ in human fibroblasts and in transformed GFSH-R17 rat granulosa cells in vitro. Mutation Research-Genetic Toxicology and Environmental Mutagenesis, 583, 178-183.

Dockerty, J.D., Elwood, J.M., Skegg, D.C. and Herbison, G.P. (1998) Electromagnetic field exposures and childhood cancers in New Zealand. Cancer Causes and Control, 9(3), 299-309.

EL-Bakatoushi, R. (2010) Genetic diversity of winter wheat (Triticum aestivum L.) growing near a high voltage transmission line. Romanian Journal of Biology-Plant Biology, 55(2), 71-87.

El-Shanshoury, A., Elshafy, E., Hamoud, M. and Elhiti, M. (2005) Molecular studies on regenerated salt tolerant cell lines of rice. Egyptian Journal of Experimental Biology (Botany), 1, 11-20.

Evans, D.A., Sharp, W.R. and Medina-Filho, H.P. (1984) Somaclonal and gametoclonal variation. American Journal of Botany, 71(6), 759-774.

Floderus, B., Persson, T., Stenlund, C., Linder, G., Johansson, C., Kiriranta, J., Parsman, H., Lindblöm, 
M., Wennberg, A., Öst, A. and Knave, B. (1993) Occupational exposure to electromagnetic fields in relation to leukemia and brain tumor: A case-control study in Sweden. Cancer Cause Control, 4, 465-476.

Garcia-Sagredo, J.M. and Monteagudo, J.L. (1991) Effect of low-level pulsed electromagnetic fields on human chromosomes in vitro: analysis of chromosomal aberrations. Hereditas, 115, 9-11.

Gangwar, A.K. and Chishti, F. (2014) Study of electromagnetic field and its effect on human body. International Journal of Advanced Research in Electrical, Electronics and Instrumentation Engineering, 7(6), 10156-10161.

Goldsworthy, A. (2006) Effects of electrical and electromagnetic fields on plants and related topics. In: "Plant Electrophysiology-Theory \& Methods" Volkov, A.G. (Ed.), pp 247-267. Springer-Verlag Berlin Heidelberg.

Ha, B.Y. (2001) Stabilization and destabilization of cell membranes by multivalent ions. Physical Review E, 64, 051902- 051907.

Hanafy, M.S., Mohamed, H.A. and Abd El-Hady, E.A. (2006) Effect of low frequency electric field on growth characteristics and protein molecular structure of wheat plant. Romanian Journal of Biophysics, 16(4), 253-271.

Hepler, P.K. and Wayne, R. (1985) Calcium and plant cell development. Annual Review of Plant Physiology, 38, 397-439.

Jajte, J.M. (2000) Programmed cell death as a biological function of electromagnetic fields at a frequency of (50/60 Hz). Medycyna Pracy, 51, 383-389.

Kheifets, L., Repacholi, M., Saunders, R. and van Deventer, E. (2005) The sensitivity of children to electromagnetic fields. Pediatrics, 116, 303-313.

Koa, K.N. (1975) A chromosomal staining method for culture cells. In: "Plant Tissue Culture Methods" Ch.10, Gamborg, O.L. and Wetter, L.R. (Ed.) National Research Council of Canada, Ottawa, Ontario.

Lai, H. and Singh, N.P. (1996) Single and double-strand DNA breaks in rat brain cells after acute exposure to radiofrequency electromagnetic radiation, International Journal of Radiation Biology, 69, 513521.
Massaro, E.J. and Markert, C. (1968) Protein staining on starch gels. Journal of Histochemistry and Cytochemistry, 16, 380-382.

McDonald, G. and Paulsen, G. (1997) High temperature effects on photosynthesis and water relations of grain legumes. Plant and Soil, 196, 47.

Murphy, J.C., Kaden, D.A., Warren, J. and Sivak, A. (1993) Power frequency electric and magnetic fields: A review of genetic toxicology. Mutation Research/ Reviews in Genetic Toxicology, 296(3), 181-296.

Nguyen, H.P., Pham, V.T.H., Baulin, V., Croft, R.J., Russell, J., Crawford, R.J., Elena, P. and Ivanova, E.P. (2017) The effect of a high frequency electromagnetic field in the microwave range on red blood cells. Scientific Report, 7, 10798.

Oral, B., Guney, M., Ozguner, F., Karahan, N., Mungan, T., Comlekci, S. and Cesur, G. (2006) Endometrial apoptosis induced by a $900-\mathrm{MHz}$ mobile phone: preventive effects of vitamins $\mathrm{E}$ and C. Advanced in Therapy, 23, 957-973.

Orrenius, S., Zhivotovsky, B. and Nicotera, P. (2003) Regulation of cell death: The calcium-apoptosis link. Nature Review of Molecular Cell Biology, 4, 552565.

Ott, H. (1976) "Noise Reduction Techniques in Electronic Systems", pp.155-156. Wiley Interscience.

Phillips, J.L., Singh, N.P. and Lai, H. (2009) Electromagnetic fields and DNA damage. Pathophysiology, 16, 79-88.

Piacentini, M.P., Fraternale, D., Piatti, E., Ricci, D., Vetrano, F., Dachà, M. and Accorsi, A. (2001) Senescence delay and change of antioxidant enzyme levels in Cucumis sativus L. etiolated seedlings by ELF magnetic fields. Plant Science, 161(1), 45-53.

Pınar, E., Vardar, F., Birbir, Y., Deniz, İ. and Meral, Ü. (2010) Cytotoxic Effects of an electromagnetic fields on the meristematic root cells of lentils (Lens clunaris Medik). Fresenius Environmental Bulletin, 19(3), 481-488.

Pourlis, A.F. (2009) Reproductive and developmental effects of EMF in vertebrate animal models. Pathophysiology, 16, 179-189.

Promila, R., Sima, B., Runthala, P. and Bhattacharya, S. 
(1991) Effect of magnetic field on the living cells of Allium cepa L. Cytologia, 56(1), 63-72.

Rajendra, P., Sujatha, H.N., H.S., Sashidhar, R.B., Subramanyam, C., Devendranath, D., Gunasekaran, B., Aradhya, R.S.S. and Bhaskaran, A. (2005) Effects of power frequency electromagnetic fields on growth of germinating Vicia faba L., the broad bean. Electromagnetic Biology and Medicine, 24(1), 39-54.

Rajendra, P., Sujatha, H.N., Sashidhar, R.B., Subramanyam, C., Devendranath, D. and Aradhya, R.S.S. (2012) Viability of unstimulated lymphocytes exposed to extremely low frequency electromagnetic fields is dependent on intensity. Biodiscovery, 2, e8925.

Rathore, K.S. and Goldsworthy, A. (1985) Electrical control of shoot regeneration in plant tissue cultures. Biotechnology, 3, 1107-1109.

Rohlf, F.J. (2000) NTSYS-pc: Numerical Taxonomy and Multivariate Analysis System, Version 2.1, Exeter Software, New York, USA.

Sander, R., Brinkmann, J. and Kuöhne, B. (1982) Laboratory studies on animals and human beings exposed to $50 \mathrm{~Hz}$ electric and magnetic fields. CIGRE, International Cong. Large High Voltage Electric Syst. September 1-9, Paris, Abstract number 36-01.

Schnepf, E. (1986) Cellular polarity. Annual Review. Plant Physiology, 37, 23-47.

Shabrangi, A., Majd, A. and Sheidai, M. (2011) Effects of extremely low frequency electromagnetic fields on growth, cytogenetic, protein content and antioxidant system of Zea mays L. African Journal of Biotechnology, 10(46), 9362-9369.

Simkó, M. (2007) Cell type specific redox status is responsible for diverse electromagnetic field effects. Current Medicinal Chemistry, 14, 1141-1152.

Sudsiri, C.J., Jumpa, N., Kongchana, P. and Ritchie, R.J. (2017) Stimulation of oil palm (Elaeis guineensis) seed germination by exposure to electromagnetic fields. Scientia Horticulturae, 220, 66-77.

Timms, A.E. and Horwitz, M. (2010) KLHDC8B in Hodgkin lymphoma and possibly twinning. Journal of Communicative and Integrative Biology, 3(2), 154-8.
Walleczek, J. (1992) Electromagnetic field effects on cells of the immune system: the role of calcium signaling. Federation of American Societies for Experimental Biology Journal, 6, 3177-3185.

Williams, J.K., Kubelisk, A.R., Livak, K.J., Rafalski, J.A. and Tingey, S.V. (1990) DNA polymorphisms amplified by arbitrary primers are useful as genetic markers. Nucleic Acids Research, 18, 6531-6535.

Xu, C., Yu, Y., Zhang, Y., Li, Y. and Wei, S. (2017) Gibberellins are involved in effect of nearnull magnetic field on Arabidopsis flowering. Bioelectromgnetics, 38(1), 1-10.

Ynikiene, S. and Pozeliene, A. (1998) The separation of vegetable seed in an electric field. Zemes Ukio Inzinerja Mokslo Darbai, 30(1), 105-110.

Yu, S.P., Canzoniero, L.M.T. and Choi, D.W. (2001) Ion homeostasis and apoptosis. Current Opinion of Cell Biology, 13, 405-411.

Zar, J.H. (1999) "Biostatistical Analysis". $4^{\text {th }}$ ed., Prentice Hall, Upper Saddle River, USA.

Zhang, H. and Hashinaga, F. (1997) Effects of high electric fields on the germination and early growth of some vegetable seeds. Journal of the Japanese Society for Horticultural Science, 66, 347-152.

Zhao, T.Y., Zou, S.P. and Knapp, P.E. (2007) Exposure to cell phone radiation up-regulates apoptosis genes in primary cultures of neurons and astrocytes. Neuroscience Letter, 412, 34-38.

Zhu, K., Hunter, S., Payne-Wilks, K., Roland, C.L. and Forbes, D.S. (2003) Use of electric bedding devices and risk of breast cancer in African-American women. American Journal of Epidemiology, 158 (8), 798-806.

Zeidali, E., Rostami, Z., Darabi, F., Soheyli, E., Nabiyouni, G. and Naseri, R. (2017) Germination and growth of wheat and wild oat seedling as affected by different intensities and times of magnetic fields. Biological, Environmental and Agricultural Sciences, 2, 86-100.

(Received 23/ 2/2018; accepted 7 / 5 /2018) 


\section{التأثثرات البيوكيميائية، الجزيئية والمطفرة للمجالات الكهرومغناطيسية على بادرات نبات

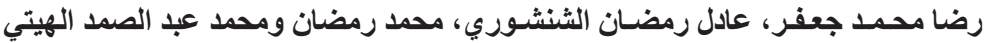

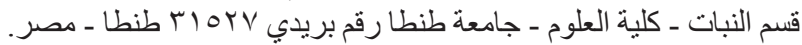

تتكون المجالات الكهرومغناطيسية من اثثين من المجالات الرئيسية الكهربائية والمغناطيسية، وتعتبر المجالات

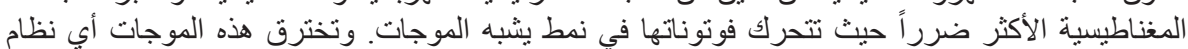

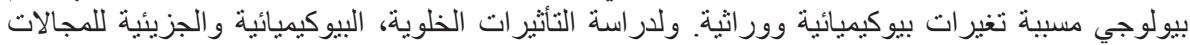

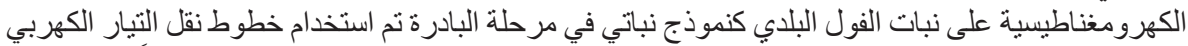

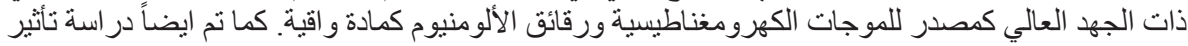

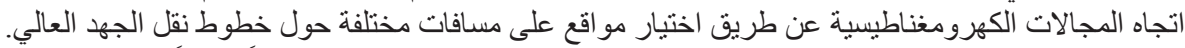

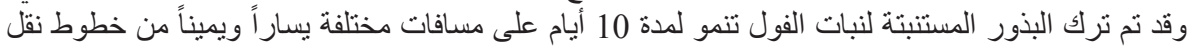

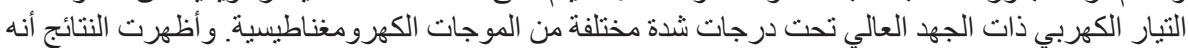

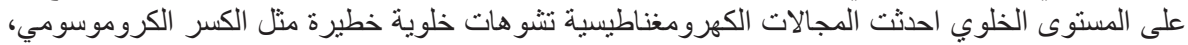

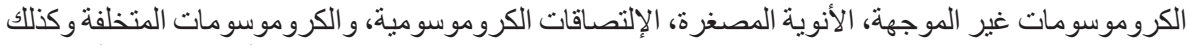

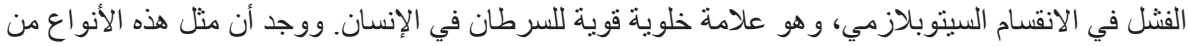

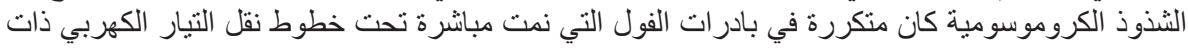

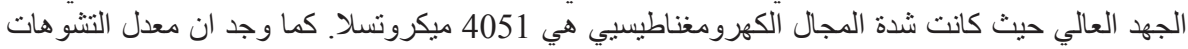

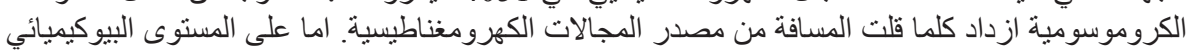

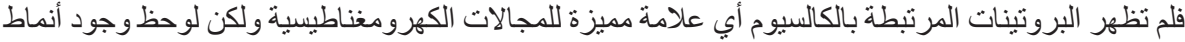

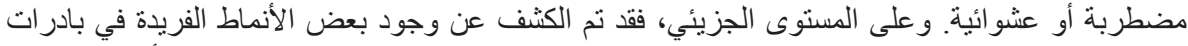

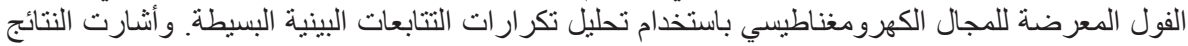

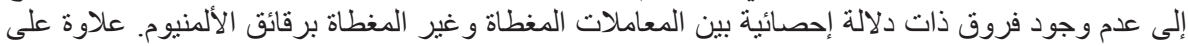

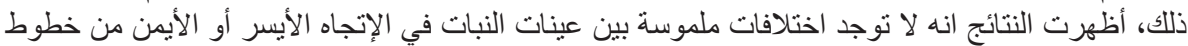

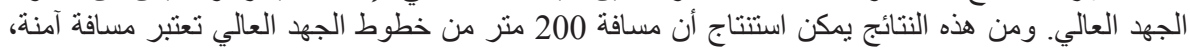

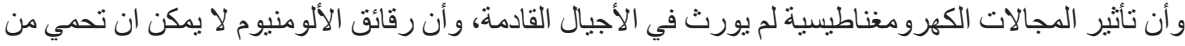
المجالات الكهرومغناطيسية. 